\title{
A IMPORTANCIA DO TRABALHO DE CAMPO PARA O ENSINO/APRENDIZAGEM DA CIDADE DE FEIRA DE SANTANA
}

\author{
Muana Silva de Almeida ${ }^{1}$; Célia Regina Batista dos Santos²; \\ 1. Bolsista PROBIC/CNPq, Graduando em Licenciatura em Geografia, Universidade Estadual de Feira de Santana, e-mail: \\ muana_muk@hotmail.com, \\ 2. Orientador: Profa. Dra. Departamento de Educação, Universidade Estadual de Feira de Santana, e-mail: \\ celiaregina2006@hotmail.com
}

\section{PALAVRAS-CHAVE: TRABALHO DE CAMPO. FEIRA DE SANTANA. MATERIAL DIDÁTICO/PEDAGOGICO}

\section{INTRODUÇÃO}

Os lugares específicos, a exemplo de Feira de Santana, são poucos explorados nos livros didáticos, que abordam apenas as cidades que tem grande influência socioeconômica no país. No nosso entendimento, isso se deve principalmente ao fato de que quem os escreve não conhece a importância e a relevância desta cidade no cenário nacional. Por não ser contemplada pelos livros didáticos, é perceptível que assuntos referentes a cidade ou ao município de Feira de Santana não fazem parte da grade curricular das escolas feirenses, e raramente são abordados nas salas de aulas. Durante as aulas de Geografia pouco são trabalhados lugares de vivencia dos alunos para que se possa criar uma ligação com o seu cotidiano. Dessa forma, há uma dificuldade dos alunos de perceberem as relações que são estabelecidas ao seu redor como tempo-espaço, natureza-sociedade, natureza-cultura, lugarmundo, cidade-campo, homem-cidade que estão diretamente ligados ao seu cotidiano. A partir desse contexto, a cidade como lugar acaba ficando "desconhecida" pelos estudantes, que muitas vezes não percebem as mudanças que a sociedade, o mapa, e o desenho que a cidade vem sofrendo ao longo do tempo.

Entendemos que a compreensão dessa realidade deve ter início na escola, porém, os resultados da pesquisa de doutorado de Santos (2007) indicou lacunas nos saberes dos professores de Geografia das escolas públicas de Feira de Santana acerca dessa temática, ressaltando o grande desafio a ser enfrentado pelos mesmos devido à ausência de materiais didáticos específicos e, principalmente, a falta de conhecimentos mais sistematizados sobre esta cidade. Na perspectiva de contribuir para amenizar essa ausência de material e de conhecimento sobre a cidade, o Grupo de Estudos e Pesquisa Lugar, Formação Docente e Elaboração de Material Didático Pedagógico sobre Feira de Santana/BA desenvolve uma pesquisa-ação de caráter colaborativo com o objetivo de ampliação dos conhecimentos sobre a cidade e elaboração de material didático-pedagógico e de atividades voltadas para o estudo de Feira de Santana. E uma das estratégias a ser utilizada pelo grupo de pesquisa para estudar a referida cidade é a articulação entre os estudos teóricos e os trabalhos de campo.

$\mathrm{Na}$ pesquisa maior os trabalhos de campo sobre Feira de Santana serão planejados de forma a serem visitadas e observadas áreas/fenômenos específicos na cidade; e as informações registradas através de filmagens, fotografias, entrevistas, descrição da paisagem, desenhos, mapeamento entre outros. Ou seja, informações/elementos/recursos que possam subsidiar a composição das temáticas/problemáticas a serem abordadas nos materiais didáticos e sugestão de atividades para o ensino e a aprendizagem deste lugar. Diante disso, o presente trabalho foi orientado pelo seguinte questionamento: Quais informações podem ser produzidas sobre a cidade de Feira de Santana, no âmbito de um trabalho de campo, que sirva de subsídios para elaboração de materiais didáticos/pedagógicos sobre esse lugar? Para responder a essas indagações, foram estabelecidos os seguintes objetivos: produzir, organizar e analisar informações coletadas através de trabalhos de campo, 
desenvolvidos em lugares/fenômenos específicos da cidade, para subsidiar a elaboração de materiais didático/pedagógicos sobre Feira de Santana; participar do planejamento e realização de trabalhos de campo em lugares específicos na cidade de Feira de Santana, eleitos pelo grupo como importantes fontes de pesquisa; produzir e sistematizar dados a partir de observação, descrição, filmagens, fotografias, entrevistas entre outros; averiguar como as informações coletadas podem ser utilizadas como fonte de dados para os materiais didáticos sobre Feira de Santana; analisar a cidade de Feira de Santana como espaço de aprendizagem e a importância pedagógica do trabalho de campo para o seu estudo nas escolas.

\section{METODOLOGIA}

Este trabalho teve por objetivo produzir, organizar e analisar informações coletadas através de trabalhos de campo, desenvolvidos em lugares/fenômenos específicos da cidade, para subsidiar a elaboração de materiais didático/pedagógicos sobre Feira de Santana. O trabalho foi desenvolvido a partir da perspectiva da pesquisa qualitativa, que apesar de se esperar um resultado especifico, não se mantem preso a esse fato simplesmente.

Inicialmente, foram planejadas várias visitas as lagoas para coleta e produção de dados, porém, o corte do transporte para o trabalho de campo devido às restrições orçamentárias da UEFS, prejudicou muito a realização desse objetivo e os membros do Grupo de Estudo e Pesquisa Lugar/Feira de Santana conseguiram realizar apenas um dos trabalhos de campo que estavam programados, através de transporte próprio durante o desenvolvimento do presente plano de trabalho. Assim sendo, para o desenvolvimento deste único campo, optamos pela visita a apenas três lagoas: Lagoa da Pindoba, Lagoa do Prato Raso (Parque do Geladinho) e Lagoa Grande, na cidade de Feira de Santana, definindo como data para a realização do trabalho de campo o dia 14 de junho de 2016. Mesmo com a disposição de todos os membros para visitar, entrevistar, filmar, fotografar as lagoas, o trabalho ficou prejudicado devido à grande quantidade de chuvas que caiu nesse dia. Após as visitas percebeu-se a necessidade de se questionar professores que fazem trabalhos de campo em suas disciplinas para saber como é planejado e como ocorre o seu desenvolvimento, principalmente para saber se eles desenvolvem trabalhos de campo no município de Feira de Santana.

\section{ANÁLISE E DISCUSSÃO DOS RESULTADOS}

Entende-se por trabalho de campo a parte pratica dos conteúdos discutidos teoricamente, na perspectiva de ajudar o indivíduo a compreender e entender as diversidades das mudanças que acontecem no espaço geográfico real que estão conhecendo. Para Silveira (2012, p.06) "O trabalho de campo é o prolongamento das aulas, uma atividade que deve ser considerada uma avaliação contínua".

No curso de Licenciatura em Geografia da UEFS, vários componentes curriculares contem em sua ementa a realização de trabalhos de campo que possibilitam aos alunos, futuros professores, realizarem a articulação teórico/prática entre os conceitos estudados e a realidade espacial concreta. Sendo assim, investigamos três professores para conhecer o seu entendimento sobre essa importante atividade.

O trabalho de campo é um método de ensino e de aprendizagem, que exige de todos os envolvidos tempo de planejamento, de execução e requer cuidados na escolha do tema. Quem propõe o campo deve procurar a organização das atividades a serem realizadas, ou seja, deve-se planejar cuidadosamente esse trabalho. Para isso, é necessário, tanto para o professor quanto para o aluno, que procurem obter conhecimentos prévios da área a ser estudada e sobre o tema do estudo. Isto se faz por intermédio da consulta bibliográfica 
(livros, artigos) e da consulta a mapas, fotos e outras fontes que contenha informações básicas do local. Como salienta Silveira (2012, p.03):

Este método é uma experiência que exige tempo de planejamento, de execução e requer cuidados na escolha do tema: onde se deve procurar a organização das atividades a serem realizadas em campo, ou seja, elaborar o plano de trabalho.

Partindo do princípio da necessidade de compreender o conteúdo estudado como referencial teórico/pedagógico para o ensino da disciplina geografia, são realizados campos para que se possa articular a teoria com a realidade estudada. Porém, quando se refere ao estudo da cidade de Feira de Santana, constatamos que tal cidade não é contemplada nos trabalhos de campo, pois quando indagados sobre os locais onde desenvolviam esse tipo de estudo, os professores responderam: Porto Seguro, Morro do Chapéu e Lençóis, na Chapada Diamantina. Apenas uma professora respondeu que desenvolve trabalho de campo na cidade de Feira de Santana, mas por que está envolvida numa pesquisa. Outro fato interessante é que os quatro investigados não são naturais desta cidade, afirmando como locais de nascimento: Manaus, São Paulo, Petrolina e Vitória da Conquista. Será que esse fato teria alguma relação com a não abordagem da cidade de Feira de Santana durante seus campos? Fica aí a questão. Tais respostas corroboram ainda mais com o nosso argumento sobre a importância do desenvolvimento de trabalhos de campo na cidade de Feira de Santana

\section{Trabalho de campo na cidade: visitação aos Olhos D’água de Santana}

Partimos do entendimento que a compreensão da realidade do lugar de vivência, que na presente pesquisa está circunscrito à cidade de Feira de Santana, deve ter início na escola. E uma das estratégias a ser utilizada pelo Grupo de Pesquisa Lugar para estudar a referida cidade é a articulação entre os estudos teóricos e os trabalhos de campo. Como procedimento de pesquisa, o trabalho de campo pode ser entendido como um estudo científico no local onde o fenômeno estudado ocorre de forma natural, e envolve a coleta e/ou registro de dados, relativas ao objeto de estudo. No âmbito pedagógico, é uma atividade que ocorre fora do ambiente escolar, cujo objetivo principal é de fornecer aos estudantes a oportunidade de aprender Geografia (História, Biologia entre outros) mediante a observação direta, na perspectiva de apreender a relação entre a teoria e os aspectos da realidade físicos - naturais e da sociedade.

Tanto como procedimento de pesquisa (acadêmica), quanto como atividade pedagógica (escolar), o trabalho de campo na/da cidade de Feira de Santana deve partir do entendimento da cidade como espaço de aprendizagem, compreendendo a sua função, sua gênese e o processo histórico em que foi produzida, estabelecendo uma nova referência para a geografia acadêmica e escolar. Do ponto de vista prático (seja como procedimento de coleta de dados, seja, como recurso didático), adota-se o trabalho de campo como um momento em que podemos visualizar tudo o que foi visto nos estudos, em que a teoria se torna realidade (MARCO, 2006, apud CASTELLAR E VILHENA, 2012, p.120).

Foi com esse entendimento que no dia 14 de junho de 2016 realizamos um trabalho de campo visitando, inicialmente, a Lagoa da Pindoba (pela sua proximidade a universidade), a Lagoa do Prato Raso (Parque do Geladinho) e, por fim, uma passagem rápida pela Lagoa Grande, para conhecer a individualidade e realidade que cada uma vive atualmente e se as informações e estudos realizados preliminarmente condiziam com o que era apresentado na realidade.

No dia destinado ao trabalho de campo estava chovendo muito e os poucos minutos de estiagem nos permitia prosseguir com o campo. Como não tínhamos transporte da UEFS o campo foi feito uma parte a pé e a outra com carros próprios de professores membro do grupo de pesquisa e que estavam responsáveis pelo trabalho campo. 
A primeira lagoa que foi visitada foi a da Pindoba que está localizada ao lado da Universidade Estadual de Feira de Santana (UEFS) no bairro do Novo Horizonte, Feira de Santana - BA. O segundo local a ser visitado foi o Parque da Lagoa do Geladinho que é uma das partes da Lagoa do Prato Raso que está localizada na Av. José Falcão da Silva, no bairro Queimadinha, Feira de Santana - BA. O último local a ser visitado foi a Lagoa Grande que está localizada no bairro da Rocinha, e possui este nome por ter sido uma das maiores lagoas situadas no perímetro urbano nos anos cinquenta.

Durante o trabalho de campo foram realizadas entrevistas, produzidas fotos e filmagens que estão sendo selecionados para que possam ser utilizados posteriormente na construção de material didático sobre as lagoas de Feira de Santana. A partir desse material que será construído trazer para sala de aula a importância de conhecer a cidade e o município.

As lagoas foram escolhidas por ser um dos elementos principais para o surgimento da cidade de Feia de Santana, que fazia com esta fosse parada obrigatória para vaqueiros que aqui passavam. Essas três lagoas forma escolhidas especificamente pela sua localidade e para que se fosse possível observar como a acontece as revitalizações e por quê nem todas são contempladas por esses projetos.

Dessa forma percebe-se a relevância desta pesquisa para que se tenha a percepção, compreensão, entendimento e o desenvolvimento dos trabalhos de campo visando o conhecimento da cidade de Feira de Santana como lugar, mas que é negligenciada tanto no ensino básico, quanto por disciplinas do curso de graduação durante o período da formação para a docência.

\section{CONSIDERAÇÕES FINAIS}

De acordo com a discussão teórica existente na literatura que aborda essa temática, pode-se compreender a importância do estudo de lugar e do trabalho de campo para o desenvolvimento de atividades didático pedagógicas diferenciadas para a formação do indivíduo enquanto sujeito do processo ensino-aprendizagem.

A partir do campo feito nas lagoas de Feira de Santana foi possível produzir materiais como fotografias, filmes e áudios para que, posteriormente, essas informações sejam selecionadas para a elaboração de um material didático embasado nas lagoas da cidade de Feira de Santana. Dessa forma, observa-se que a realização de trabalhos campo torna-se uma importante estratégia de ensino e aprendizagem para o estudo da cidade, possibilitando a articulação entre as teorias estudadas e a realidade vivida, fazendo com que o indivíduo conheça mais a sua cidade e passe a entende-la como lugar.

\section{REFERENCIAS}

CASTELLAR, Sonia; VILHENA, Jerusa. Ensino de Geografia. São Paulo: Cengage Learning, 2012.

SILVEIRA, Janete Aparecida Nunes da. Trabalho de Campo. Revista Tessituras Geográficas-FACOS / CNEC Osório vol.1 - nº 1 - issn 2317 - 4471 - dez / 2012 